Www.jmscr.igmpublication.org

Impact Factor (SJIF): 6.379

Index Copernicus Value: 79.54

ISSN (e)-2347-176x ISSN (p) 2455-0450

crossrefDOI: https://dx.doi.org/10.18535/jmscr/v6i11.50

Journal Of Medical Science And Clinical Research

IGM Publication

An Official Publication of IGM Publication

\title{
Post-operative Pulmonary Complications in Elderly Patients Undergoing Elective Open Upper Abdominal Surgery under General Anaesthesia
}

\author{
Authors \\ Mohamad Azhar Gilani ${ }^{1}$, Shahina Parveen ${ }^{2}$, Syed Najmul Ain ${ }^{3 *}$, Zahoor Ahmad Bhat ${ }^{4}$, \\ Ubaidullah Gul Salmani ${ }^{5}$, Rashid Javaid Fazili ${ }^{6}$ \\ ${ }^{1,6}$ Senior Resident, Department of Anaesthesiology, Government Medical College Srinagar, \\ ${ }^{2}$ Associate Professor, Department of Anaesthesiology, Government Medical College Srinagar, \\ ${ }^{3}$ Post-graduate student, Department of Social and Preventive Medicine, Government Medical College Srinagar, \\ ${ }^{4}$ Post-graduate Diploma, Department of Anaesthesiology, Government Medical College Srinagar, \\ ${ }^{5}$ Post-graduate student, Department of Anaesthesiology, Government Medical College Srinagar \\ *Corresponding Author \\ Syed Najmul Ain
}

\begin{abstract}
Background: Postoperative pulmonary complications are an important factor responsible for the mortality and morbidity in the post-operative period after surgery and may also increase the length of stay in the hospital.

Objectives: To find out the incidence of pulmonary complications post-operatively among elderly patients after elective open upper abdominal surgery under general anaesthesia and to study the effect of preexisting respiratory ailments on post-operative pulmonary complications.

Methodology: This was a hospital based cross-sectional study conducted in the department of anaesthesiology, GMC Srinagar.

Results: Postoperatively, $49 \%$ of the patients had SPO2 less than $94 \%$ while on auscultation, there was decreased air entry in about $42 \%$ of the patients. On chest X-Ray, the major finding was collapse in $15 \%$ of the patients postoperatively. The respiratory rate was increased in $28 \%$ of the patients.

In total, about $55 \%$ of the patients had post-operative pulmonary complications. The presence of preoperative pulmonary complications was associated with the development of respiratory complications in the post-operative period ( $p<0.001)$.

Conclusion: The presence of preoperative respiratory symptoms was the most important risk factor for the development of postoperative pulmonary complications.
\end{abstract}

\section{Introduction}

Postoperative pulmonary complications are an important factor responsible for the mortality and morbidity in the post-operative period after surgery and may also increase the length of stay in the hospital. There may be multiple causes for post-operative pulmonary complications including the pre-operative health status of the patient, type of surgery, duration of surgery, the type of anaesthesia and many more. Obesity, smoking, age and sex of the patient and other co-morbidities are patient risk factors. These factors may act synergistically. The incidence of post-operative pulmonary complications varies ranging from $2 \%$ to $40 \%$. $^{1,2}$ 


\section{Objectives}

1. To find out the incidence of pulmonary complications post-operatively among elderly patients after elective open upper abdominal surgery under general anesthesia.

2. To study the effect of pre-existing respiratory ailments on the post-operative pulmonary complications.

\section{Methodology}

This study was a cross-sectional hospital based study which was conducted in the department of Anesthesiology, SMHS hospital, Government Medical College, Srinagar. The period of study was from 2015 to 2017 with 1 year of data collection. The study was approved by the local committee and each patient's consent was sought before participating in this study.

\section{Inclusion Criteria}

1) Patients undergoing elective open upper abdominal surgery under general anesthesia.

2) Patients who are willing to participate and provide a written informed consent.

3) Patients aged $>60$ years.
Exclusion Criteria: Patients who remained intubated after surgery were excluded.

Data Collection: At the baseline, thorough history taking, general physical examination, systemic examinations and all the routine tests were performed for each patient and important findings noted pre-operatively. After the surgery was over, the findings on general physical examination, systemic examination and the findings on the routine tests were noted.

Any patient who had derangement of any of the respiratory parameters was considered to have a pulmonary complication. The parameters were recorded at the time of admission for the surgery and also at 48 hours after the surgery for this study.

SPO2 of $<95 \%$ and a respiratory rate of $>20$ were considered to be deranged as per the evidence from literature. ${ }^{3,4}$

\section{Results}

In the study period a total of 53 patients fulfilling the eligibility criteria were included in the study.Table 1 shows the general characteristics of the patients in our study.

Table 1: General characteristics of the patients

\begin{tabular}{|l|c|c|c|}
\hline \multirow{3}{*}{ Gender } & & Number & Percentage \\
\hline \multirow{3}{*}{ Age group } & Male & 31 & 58.5 \\
\cline { 2 - 4 } & Female & 22 & 41.5 \\
\hline Smoking status & $\leq 75$ years & 33 & 62.3 \\
\cline { 2 - 4 } & $\geq 76$ years & 20 & 37.7 \\
\hline Co-morbidities* & Smoker & 26 & 49.1 \\
\cline { 2 - 4 } & Non-smoker & 27 & 50.9 \\
\cline { 2 - 4 } & Hypertension & 11 & 20.8 \\
\cline { 2 - 4 } & Diabetes Mellitus & 9 & 17.0 \\
\cline { 2 - 4 } & Hypothyroidism & 5 & 9.4 \\
\cline { 2 - 4 } & Asthma & 2 & 3.8 \\
\cline { 2 - 4 } & COPD & 1 & 1.9 \\
\cline { 2 - 4 } & No Comorbidity & 28 & 52.8 \\
\hline & Total & 53 & 100.0 \\
\hline
\end{tabular}

*The total of comorbidities does not some up to 53 as some patients had more than one comorbidity and the percentages of comorbidities have been calculated with a denominator of 53 .

There were more men $(58.5 \%)$ in our study compared to women (41.5\%). Maximum patients belonged to the age group of less than 75 years $(62 \%)$. The mean age was found out to be 72.5 years with a standard deviation of 7.5 years. About $49 \%$ of the patients were smokers while the rest were non-smokers. The most common comorbidity among our study subjects was hypertension with about $21 \%$ of the patients having hypertension followed by diabetes which was present in $17 \%$ of the patients. 
Hypothyroidism was present in $10 \%$ of the patients while Asthma and COPD were present in lesser percentages. At least one comorbidity was present in $47 \%$ of the patients.

Table 2: Preoperative pulmonary findings of the patients

\begin{tabular}{|l|c|c|c|}
\hline \multicolumn{2}{|c|}{ Parameter* } & Number & Percentage \\
\hline \multirow{2}{*}{ SO2 } & $\leq 94 \%$ & 9 & 17.0 \\
\cline { 2 - 4 } & $\geq 95 \%$ & 44 & 83.0 \\
\hline \multirow{2}{*}{ Auscultatory findings } & Air entry normal & 50 & 94.3 \\
\cline { 2 - 4 } & Wheeze & 3 & 5.7 \\
\hline \multirow{2}{*}{$\begin{array}{l}\text { Chest X-Ray } \\
\text { Pre-operative pulmonary } \\
\text { complications }\end{array}$} & Clear & 51 & 96.2 \\
\cline { 2 - 4 } & Hyperinflated & 2 & 3.8 \\
\cline { 2 - 4 } & Yes & 9 & 17 \\
\hline & No & 44 & 83 \\
\hline
\end{tabular}

*Preoperatively, the respiratory rate was normal in all patients.

Pre-operatively we had $17 \%$ of the patients having SPO2 less than 94\%. On auscultation, about $6 \%$ of the patients had wheeze and on chest X-Ray lung fields were clear in $96 \%$ of the patients. Only $17 \%$ of the patients had pre-operative pulmonary complications. A patient having at least one

Table 2 shows the preoperative findings in our patients. abnormal parameter among the following i.e., $\mathrm{SPO}$, auscultatory findings, chest $\mathrm{X}$-ray findings or respiratory rate, was considered to have a preoperative pulmonary complication.

Table 3 shows the post-operative findings of the patients.

Table 3: Postoperative findings among the patients

\begin{tabular}{|c|c|c|c|}
\hline \multicolumn{2}{|l|}{ Parameter } & Number & Percentage \\
\hline \multirow[t]{2}{*}{$\mathrm{SO} 2$} & $\leq 94 \%$ & 26 & 49.1 \\
\hline & $\geq 95 \%$ & 27 & 50.9 \\
\hline \multirow[t]{3}{*}{ Auscultatory findings } & Air entry normal & 27 & 50.9 \\
\hline & Wheeze & 4 & 7.5 \\
\hline & Decreased air entry & 22 & 41.5 \\
\hline \multirow[t]{4}{*}{ Chest X-Ray findings } & Clear & 39 & 73.6 \\
\hline & Collapse & 8 & 15.1 \\
\hline & Opacity & 5 & 9.4 \\
\hline & Hyperinflated & 1 & 1.9 \\
\hline \multirow[t]{2}{*}{ Respiratory rate } & $\leq 20$ & 38 & 71.7 \\
\hline & $\geq 21$ & 15 & 28.3 \\
\hline \multirow{3}{*}{$\begin{array}{l}\text { Post-operative } \\
\text { complications }\end{array}$} & Yes & 29 & 54.7 \\
\hline & No & 24 & 45.3 \\
\hline & Total & 53 & 100.0 \\
\hline
\end{tabular}

Postoperatively, $49 \%$ of the patients had SPO2 less than $94 \%$ while on auscultation, there was decreased air entry in about $42 \%$ of the patients. On chest X-Ray, the major finding was collapse in $15 \%$ of the patients postoperatively. The respiratory rate was increased in $28 \%$ of the patients.

Considering all parameters, about $55 \%$ of the patients had post-operative pulmonary complications. A patient having at least one abnormal parameter among the following i.e., $\mathrm{SPO}$, auscultatory findings, chest X-ray findings 
Table 4a: Relationship of postoperative pulmonary complications with patient characteristics

\begin{tabular}{|c|c|c|c|c|c|}
\hline & & Present & Absent & Pearson's chi-square & $P$ value \\
\hline \multirow[t]{2}{*}{ Gender } & Male & $19(61.3 \%)$ & $12(38.7 \%)$ & \multirow[t]{2}{*}{1.302} & \multirow[t]{2}{*}{0.254} \\
\hline & Female & $10(45.5 \%)$ & $12(54.5 \%)$ & & \\
\hline \multirow[t]{2}{*}{ Age-group } & $</=75$ & $17(51.5 \%)$ & $16(48.5 \%)$ & \multirow[t]{2}{*}{0.362} & \multirow[t]{2}{*}{0.547} \\
\hline & $>/=76$ & $12(60.0 \%)$ & $8(40.0 \%)$ & & \\
\hline \multirow[t]{2}{*}{ Smoking } & Smoker & $15(57.7 \%)$ & $11(42.3 \%)$ & \multirow[t]{2}{*}{0.182} & \multirow[t]{2}{*}{0.669} \\
\hline & Non-smoker & $14(51.9 \%)$ & $13(48.1 \%)$ & & \\
\hline Total & & $29(54.7 \%)$ & $24(45.3 \%)$ & & \\
\hline
\end{tabular}

Table 4b: Comparison of pre-operative pulmonary complications with post-operative complications

\begin{tabular}{|c|c|c|c|c|c|}
\hline \multirow{2}{*}{\multicolumn{2}{|c|}{ McNemar Test }} & \multicolumn{2}{|c|}{ Pre-operative pulomnary complications } & \multirow[b]{2}{*}{ Total } & \multirow{2}{*}{$\begin{array}{c}\mathrm{P} \\
\text { value }\end{array}$} \\
\hline & & Yes & No & & \\
\hline \multirow{3}{*}{$\begin{array}{l}\text { Post-operative } \\
\text { pulmonary } \\
\text { complications }\end{array}$} & YES & $\begin{array}{c}9 \\
(100.0 \%)\end{array}$ & $\begin{array}{c}20 \\
(45.5 \%)\end{array}$ & $\begin{array}{c}29(54.7 \% \\
)\end{array}$ & $<0.001$ \\
\hline & NO & $\begin{array}{c}0 \\
(0.0 \%)\end{array}$ & $\begin{array}{c}24 \\
(54.5 \%)\end{array}$ & $\begin{array}{c}24 \\
(45.3 \%)\end{array}$ & \\
\hline & Total & $9(100 \%)$ & $44(100.0 \%)$ & $53(100 \%)$ & \\
\hline
\end{tabular}

There was no relationship between the patient's gender, age or smoking status with the presence or absence of postoperative pulmonary complications. The presence of pre-operative pulmonary complications was associated with the development of respiratory complications in the post-operative period $(\mathrm{p}<0.001$, table $4 \mathrm{~b})$

\section{Discussion}

In our study, all 53 patients underwent elective open surgery under general anaesthesia and pulmonary complications occurred in 29patients (55\%).A patient having at least one abnormal parameter among the following i.e., SPO2, auscultatory findings, chest X-ray findings or respiratory rate, was considered to have a postoperative pulmonary complication. Using these basic parameters to pick up the pulmonary complications made our finding of the postoperative pulmonary complications very sensitive. Although age might have been an important risk factor, it was not found to have a role in our study since all patients were above 60 years and all fall in the geriatric age group. Gender and smoking also had no effect on the development of postoperative pulmonary complications in our study although smoking has been found to increase the risk of post-operative pulmonary complications $^{5,6}$. This effect might have been missed as the patients who smoked were advised to quit smoking at the time they got registered in the hospital for elective surgery which might have been at least 1 to 2 months before.

A significant relationship was found in the incidence of post-operative complications with the pre-operative complications $(\mathrm{p}<0.001)$. All the patients who had some pre-operative pulmonary complication also had some complication in the post-operative period while $45.5 \%$ of the patients who had no complication in the pre-operative period developed some complication in the postoperative period.

Our study had some limitations. The study was limited only to elective open abdominal surgery under general anaesthesia. The sample size was small. An important concern in this study is that we have evaluated only the patients who were operated under general anaesthesia. A question arises as to whether spinal anaesthesia or epidural anaesthesia may alter the complication rates. Also the rates may differ for laparoscopic and emergency surgeries. Therefore, we recommend more studies be conducted to evaluate all the factors that may be related to post-operative pulmonary complications.

\section{Conclusion}

In conclusion, the presence of preoperative respiratory symptoms was the most important risk factor for the development of postoperative 
pulmonary complications. We believe that the identification of the patients at high risk for postoperative pulmonary complications, the evaluation of the preoperative pulmonary risks and the management of the respiratory problems of the patients before surgery may result in an improved outcome of surgical procedures with less postoperative pulmonary complications.

Conflicts of Interest: None declared.

\section{Author contributions:}

First Author: Idea of study, data collection and write-up

Second Author: Guidance and Supervision

Third Author: Statistical analysis

$4^{\text {th }}, 5^{\text {th }}$ and $6^{\text {th }}$ authors: Review of literature

\section{References}

1. Brian K. Pre-operative pulmonary evaluation in the patient with suspected respiratory disease. IJA.2015;59(9):542549.10.4103/0019-5049.165854

2. Rock P, Rich PB. Postoperative pulmonary complications. Curr Op Anaesthesiol 2003;16:123-32.

3. Monica L, Ulf A, Audhild H, Hasse M. Predictors of oxygen saturation $\leq 95 \%$ in a cross-sectional population based survey. Respiratory Medicine (2012) 106, 15511558.http://dx.doi.org/10.1016/j.rmed.201 2,06.016

4. Michelle A, Rinaldo B, Ken H, Jack C, Simon F, Arthas F. Respiratory rate: the neglected vital sign.

5. Pereira EDB, Fernandes ALG, Ancao MDS, Peres CDA, Atallah AN, Faresin
AM. Prospective assessment of the risk of postoperative pulmonary complications in patients submitted to upper abdominal surgery. Sao Paulo Med. J. 1999;117:20 34.

6. Warner MA, Offord KP, Warner ME, Lennon RI, Conover MA, JansonSchumacher U. Role of preoperative cessation of smoking and other factors in postoperative pulmonary complications: a blinded prospective study of coronary artery bypass patients. Mayo Clin. Proc. 1989; 64: 609-16. 